\title{
Collaborative Experiential Learning Model
}

\author{
Minal Salunke', Vijayalakshmi $\mathbf{M}^{2}$, S.B. Burli ${ }^{3}$ \\ KLE Technological University, Hubballi. \\ ${ }^{1}$ minal@bvb.edu, ${ }^{2} v i j u 11 @ b v b . e d u,{ }^{3}$ sbburli@bvb.edu.
}

\begin{abstract}
An entrant to engineering has to undergo many fundamental courses in the first year of curriculum. Basic electrical engineering is one amongst these courses. The traditional way of teaching the course was teacher-centric and aid used for teaching was chalk and talk. Less emphasis was given for student interaction. Traditional style of teaching rarely gives students the opportunity to apply their newfound knowledge to actual situations, resulting in a serious time lag between students learning and applying new knowledge. As a result many students have trouble determining the relevance of what they are being taught, and thus lacking any obvious need to learn and fail to engage in the learning process. To provide an opportunity for collaborative experiential learning to reinforce the theoretical concepts imbibed in students we proposed a model on collaborative experiential learning which concentrates on the beginning of instruction referring to Fink's Model containing Knowledge of subject matter, Design of Course, Teacher-student interaction and Course management. In particular, the "Teacher-student interaction" is adopted which is an umbrella term that refers to all the different ways teachers interact with their students. For better interfacing, Kolb's experiential learning theory based on a four-stage learning cycle is applied. In addition to the above interaction in teaching learning process learning style of an individual is important to undergo different learning cycle. The three main types of learning styles are, auditory, visual, and kinesthetic. Whenever the task is given for an individual the above learning styles can be adopted, meanwhile if the task is for a team with different learning style of a student then we need to focus on style of learning. The three styles of learning are active learning, cooperative learning and problem based learning. The proposed model is applied to the course on Fundamentals of Electrical Engineering, Apart from the regular classroom teaching we used principles of instruction to select, plan and develop an activity based on Industry visit to enhance students learning. To realize the impact of learning happened through the industry visit pertaining to topics like actuators and/or sensors, the written examination was conducted and feedback at two intervals, before and after the industry
\end{abstract}

Minal Salunke ${ }^{1}$

KLE Technological University, Hubballi.

${ }^{1}$ minal@bvb.edu visit was taken. Individual question wise inferential statistical analysis using paired t- test was performed and inferred that the activity improved the knowledge and exposure level of a student.

Key words: Experiential learning, learning style, style of learning, statistical analysis

\section{Introduction}

Basic electrical engineering is one amongst the fundamental courses taught at first year level. The goal of this freshmen engineering course is to provide a platform for introducing fundamental electrical concepts such as voltage, current, magnetic flux, motor operation, and safety which will capture student interest and allow for further exploration. The traditional way of teaching the course was teacher-centric and aid used for teaching was chalk and talk. To provide an opportunity for collaborative experiential learning to reinforce the theoretical concepts imbibed in students we proposed a model on collaborative experiential learning which concentrates on the beginning of instruction referring to Fink's Model [1]. By the older method the students learning was comparatively less because course instructor failed to identify the different learning styles of the students. Traditional style of teaching rarely gives students the opportunity to apply their newfound knowledge to actual situations, resulting in a serious time lag between students learning and applying new knowledge. As a result many students have trouble determining the relevance of what they are being taught, and thus lacking any obvious need to learn and fail to engage in the learning process. Therefore, for effective classroom learning, Kolb's learning model based on four distinct learning styles is applied for this activity.

\subsection{Fink's Model}

Good teachers want good learning to occur as a result of their teaching. Good learning means, besides recalling information, the ability of problem solving, critical thinking, and creative thinking. Good learning is also referred to as meaningful learning, significant learning and/or higher orders (Apply, Analysis, Evaluate and Create categories of Bloom's taxonomy) of learning. L.D.Fink in 2003 came up with four components of teaching as depicted in the figure 1 . 


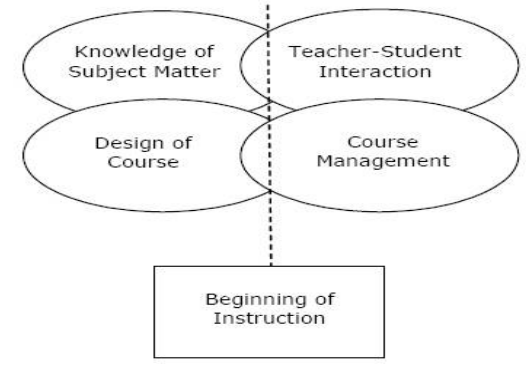

Fig. 1 Fink's Model

\subsection{Kolb's Experiential Learning Theory}

Kolb's model offers both a way to understand individual learning styles, and also an explanation of a cycle of experiential learning that applies to all learners. Kolb proposed that an individual learner moves through a spiral of immediate experience which leads to observations and reflections on the experience. These reflections are then absorbed and linked with previous knowledge and translated into abstract concepts or theories, which result in new ways and actions to adjust to the experience that can be tested and explored. Kolb described the four stages in the cycle of experiential learning as:

- $\quad$ Concrete Experience - (CE)

- $\quad$ Reflective Observation - (RO)

- $\quad$ Abstract Conceptualization - (AC)

- $\quad$ Active Experimentation - (AE)

\subsection{Learning styles}

As every learner cannot learn all the concepts with one learning style, especially the difficult concepts cannot be learnt without visualization and/ or practical exposure. So there arises a need for adopting the different learning styles for different concepts. In a teaching learning process there are three main types of learning styles: auditory, visual, and kinesthetic. Most of the students learn best through a combination of the three types of learning styles, but every student is different. The Auditory learners would rather listen to things being explained than read about them. Reciting information out loud and having music in the background may be a common study method. Other noises may become a distraction resulting in a need for a relatively quiet place. Visual learners learn best by looking at graphics, watching a demonstration, or reading. For them, it's easy to look at charts and graphs, but they may have difficulty focusing while listening to an explanation. Kinesthetic learners process information best through a "hands-on" experience. Actually doing an activity can be the easiest way for them to learn. Sitting still while studying may be difficult, but writing things down makes it easier to understand.

\subsection{Style of Learning}

Whenever the task is given for an individual the above learning styles can be adopted, meanwhile if the task is for a team with different learning style of a student then we need to focus on style of learning [3]. As per the literature there are three styles of learning they are active learning, cooperative learning and problem based learning. Active learning is generally defined as any instructional method that engages students in the learning process. In short, active learning requires students to do meaningful learning activities and think about what they are doing. The core elements of active learning are student activity and engagement in the learning process. Cooperative learning can be defined as a structured form of team work where students pursue common goals while being assessed individually. The most common model of cooperative learning found in the engineering literature is that of Johnson, Johnson and Smith [4]. This model incorporates five specific belief, which are individual accountability, mutual interdependence, face-to-face interaction, appropriate practice of interpersonal skills, and regular self-assessment of team functioning. Problem-based learning (PBL) is an instructional method where relevant problems are introduced at the beginning of the instruction cycle and used to provide the context and motivation for the learning that follows [2]. It is always active and usually (but not necessarily) collaborative or cooperative using the above definitions. PBL typically involves significant amounts of self-directed learning on the part of the students. It is not only the learning style of a student matters but also the teaching style also matters in overall learning. As an engineering subject is considered by a teacher for lecture delivery, the flow of teaching is from general to specific - first ideas, and then laws, followed by equations, and examples. However, most students seem to learn in the opposite order - first examples, then equations, followed by laws and finally ideas. Some students never go beyond studying the examples and many believe that only equations are important. When the teacher probes their understanding of the general principles through a quiz, many students give memorized solutions or protest that the concept was never taught in the class. To address these issues an activity is designed in section --- for the course Basic Electrical Engineering.

\section{COURSE}

\subsection{Importance of teaching fundamentals of electrical engineering course}

The fundamental of electrical engineering is an interdisciplinary subject of great importance in the domain of not only electrical engineering but also to the other disciplines of engineering. The basic concepts such as circuit theory, knowledge of actuators and sensors, importance of measuring instruments are the building blocks for the higher semester courses. Traditionally the 
above topics were taught only through lectures where students were unable to link it to the real world scenario and the higher level problem solving ability was poor. To address this issue an activity is designed which enhanced the learning of the students. As a part of the course, the students were asked to visit an industry related to Electrical field.

\subsection{Importance of Industry visit}

An industrial visit provides a pathway for learning and leisure and it is this experience that help students gain first hand information regarding functioning of various industries [5]. Industrial visits for engineering students have significant potential benefits for all involved. For the student, it is an opportunity to broaden their understanding of the industry and experiencing the practical application of theories learnt in class. The industry visit provides a unique experience to the students and exchange and share good practices which could be replicated to improve the efficiency, production and competency in their respective field of study. Collaborative Experiential Learning leverages the student's imagination. These visits act as a catalyst for students to acquire practical insights of the real-time environment. Industrial exposure during the formative year's results in more refined individuals, encouraging the students to see things from different perspectives and helping them to make informed decisions, acquiring transferable skills that will be useful to build a career and will remain with them for life.

\section{METHODOLOGY}

\subsection{Problem definition}

To provide an opportunity for collaborative experiential learning to reinforce the theoretical concepts imbibed in students.

\subsection{Collaborative Experiential learning}

The proposed model on collaborative experiential learning concentrates on the beginning of instruction, experiential learning, visual learning style, cooperative style of learning and assessment of the learning through activity. The model is depicted in Fig.2. For better teaching to transpire (come to light) all teachers need to have adequate knowledge of the subject matter, design instruction of their course (Course Design), interact with students, and manage course events. Generally, the first two task take place before the course begins; the other two after it begins (L.D. Fink 2003). This view implies that a teacher can improve his/her teaching leading to good learning by students by improving any or all of the four competencies.

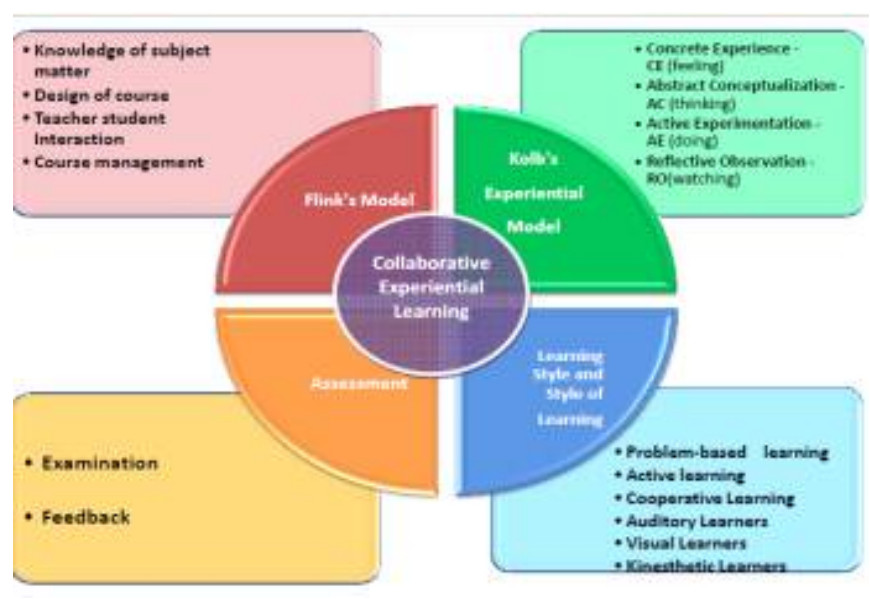

Fig. 2 Collaborative Experiential Learning Model

However, the impact of improvement in their competencies on learning by the student may not be equal. "Teacher-student interactions" is an umbrella term that refers to all the different ways teachers interact with their students: lecturing, leading class discussions, tutoring, meeting with individual students, and communicating by e-mail and so on. This aspect of teaching is a skill that runs the full spectrum from poor to excellent. "Course management" refers to conducting instructional events of the course in an organized manner. Instructional events refer to conducting the sessions as per declared time table, having assignments ready when they are needed, grading and returning test papers promptly, and so on. Out of these four aspects of teaching, the component targeted is teacher-student interaction. For better interfacing, Kolb's experiential learning theory based on a four-stage learning cycle is applied. Kolb says that ideally (and by inference not always) this process represents a learning cycle or spiral where the learner 'touches all the bases', i.e., a cycle of experiencing, reflecting, thinking, and acting. Immediate or concrete experiences lead to observations and reflections. These reflections are then assimilated (absorbed and translated) into abstract concepts with implications for action, which the person can actively test and experiment with, which in turn enable the creation of new experiences. In a teaching learning process learning style of an individual is important to undergo different learning cycle. The three main types of learning styles are, auditory, visual, and kinesthetic. Whenever the task is given for an individual the above learning styles can be adopted, meanwhile if the task is for a team with different learning style of a student then we need to focus on style of learning. The three styles of learning are active learning, cooperative learning and problem based learning. 


\section{a) The objectives of the activity}

- To understand the concepts of energy-conversion process in electromechanical systems.

- To understand the need of actuators for industrial and domestic purposes.

- To identify different classes of actuators, it's functioning and its application.

- To choose right sensor to measure all types of natural phenomena.

- Opportunities for collaborative experiential learning.

\section{b) Conduction of the activity}

- The class strength of 70 was divided into 12 teams. Each group consisted of $5-6$ students

- Team was formed on random basis.

- Each team visited the industries related to manufacturing, assembling or process.

- Each team collected the technical information related to sensors or actuators.

- Each team presented the outcome of the Industrial visit.

\section{c) Role of Teacher before and after the activity}

Apart from the regular classroom teaching the teacher should use principles of instruction to select or plan and develop activities to best help students learn.

\section{(i) Before}

- The students were brainstormed on various industries and its location.

- The students were given the supporting material necessary to increase the effectiveness of this experience.

- The students were educated regarding the dynamics of collaborative experiential learning.

- The students were told to prepare a survey questionnaire during visit.

- The students were prepared to introduce themselves to the representatives of the industry, later wrap up by thanking the industry representative/facilitator.

\section{(ii) After}

The students were evaluated for the activity: The evaluation was based on the ancillary investigation presentations and on detailed report on the location, industries and acquired knowledge.

\section{d) Outcome of Industry Visit}

Students collected technical information from the industry visited and prepared a report on same. The experience was shared through oral presentation. The snapshots taken during the visit are shown below.

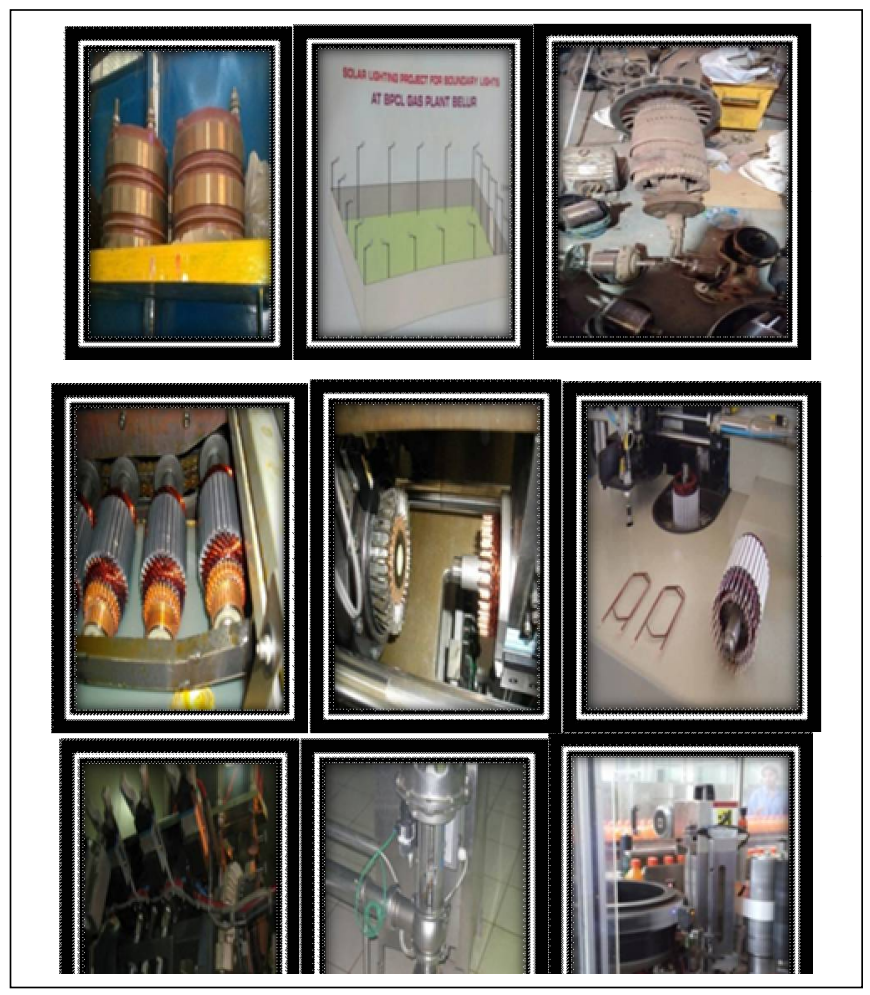

Fig 3. Sample snapshots

Few small scale industries visited by students are listed as follows:

- Patil Insulating Company Private Limited Manufactures electrical insulation material

- Kovino Industries: Manufactures Solar panels, Solar lighting systems, Batteries, Inverters and UPS systems.

- USHA Electricals- Specialist in Rewinding of Electric motors, Generators, Pumps \& Repairers of Electrical Equipments

- $\quad$ Patil Electrical Works - Manufacturers / Suppliers of different types of Electric products like electric motor, generators in a comprehensive range of reliable and high efficiency electric motors and generators for all applications.

- Shanthala Power Limited (SPL) - Testing, Calibration, Engineering Services, Project Management Consultancy and Third Party Inspection services in the field of Electrical, Electronics, Mechanical, Civil and Chemical 
Engineering services to the Industries and Utilities in India and Abroad.

- NECTAR BEVERAGES PRIVATE LIMITED Manufactures pepsi, mirinda, slice, lehar (soda),7 up, mountain dew, aquafina mineral water Applications of sensors and motors.

- Swastik wire industries - Manufactures insulated copper and aluminium conductors.

\section{e) Assessment}

Assessment was based on the presentation and report submission

Table 1 Assessment sheet

\begin{tabular}{|l|l|l|l|}
\hline SL.No. & Name of the Student & USN & Max.Marks: 10 \\
\hline 1 & & & \\
\hline 2 & & & \\
\hline 3 & & & \\
\hline 4 & & & \\
\hline 5 & & & \\
\hline
\end{tabular}

Table 2 Assessment Rubrics

\begin{tabular}{|c|c|c|}
\hline $\begin{array}{l}\text { SI. } \\
\text { No }\end{array}$ & Parameter & $\begin{array}{l}\text { Marks } \\
\text { Obtained }\end{array}$ \\
\hline 1. & $\begin{array}{l}\text { Is the chosen industry relevant to the } \\
\text { activity? }\end{array}$ & \\
\hline 2 . & $\begin{array}{l}\text { Does the student have clarity on the } \\
\text { purpose of the industry visit? }\end{array}$ & \\
\hline 3. & $\begin{array}{l}\text { Is the student able to identify the } \\
\text { relevance of using actuators and sensors? }\end{array}$ & \\
\hline 4. & $\begin{array}{l}\text { Is the student able to summarize entire } \\
\text { activity orally? }\end{array}$ & \\
\hline 5. & $\begin{array}{l}\text { Has group Activity developed ability to } \\
\text { work in team? }\end{array}$ & \\
\hline & Total & \\
\hline
\end{tabular}

Marks allotted for each question

Answer to Q.No 1 and 2. Yes (1 Mark) No (0 Mark)

Answer to Q.No 3. Identified all the relevant information (2- 3 Marks) Identified some and failed to collect all relevant information (1 Marks)

Answer to Q.No 4. Excellent (3 Marks) Good (2 Marks) Moderate (1 Mark)
Answer to Q.No 5. Active participation in team activity (1-2 Marks) Participated but no contribution (0 Marks).

\section{RESULTS}

To realize the impact of learning happened through the industry visit pertaining to topics like actuators and/or sensors, the written examination was conducted and feedback at two intervals, before and after the industry visit was taken.

\section{Analysis of minor II and SEE}

Table 3 paired T-Test on Exam Results

\begin{tabular}{|l|l|l|l|l|}
\hline \multirow{2}{*}{$\begin{array}{l}\text { Question } \\
\mathrm{s}\end{array}$} & \multicolumn{2}{|l|}{ Mean } & t Stat & $\begin{array}{l}\mathrm{P}(\mathrm{T}<=\mathrm{t}) \\
\text { one-tail }\end{array}$ \\
\cline { 2 - 4 } & MinorII & SEE & & \\
\hline 1 Mark & 2.8 & 2.75 & 0.3 & 0.8 \\
\hline 2 Mark & 4.5 & 4.1 & 0.7 & 0.5 \\
\hline 5 Mark & 7.9 & 7.6 & 0.6 & 0.5 \\
\hline 10 Mark & 14.0 & 16.3 & -2.6 & 0.0 \\
\hline
\end{tabular}

From table 3 we can observe that for 1 mark, 2 mark and 5 mark questions, there are no significant changes in mean from CIE to SEE. Whereas difference in mean is statistically significant for 10 mark questions. It can be inferred that students were able to attempt complex questions better. Fig.3. depicts the comparison of means of marks attended in CIE and SEE.

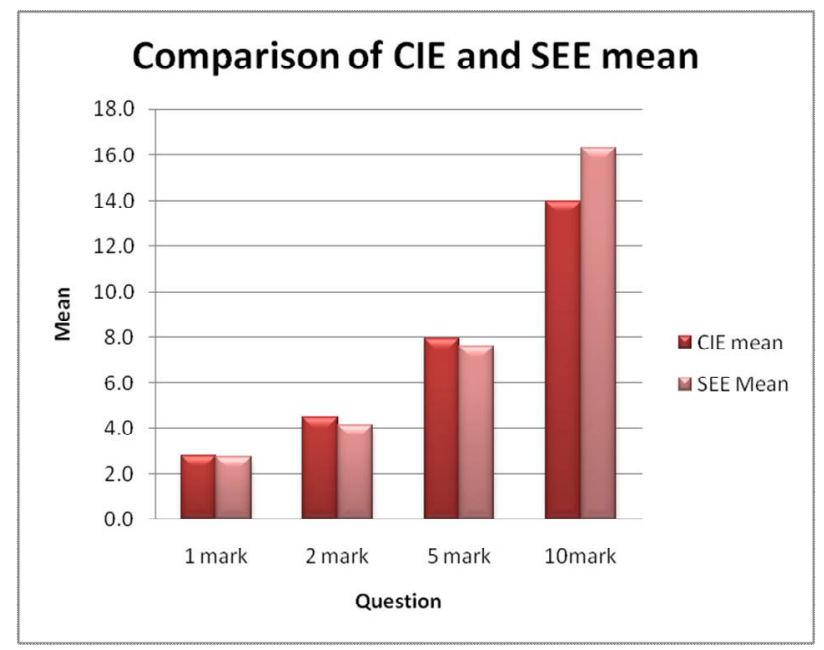

Fig.4. Comparison of CIE and SEE Mean

\section{Analysis of Feedback questionnaire}

Individual question wise inferential statistical analysis using paired t- test had been performed to identify whether the proposed activity had improved the knowledge or exposure level of a student. To check the effectiveness of 
an activity, feedback was taken. Table 4 gives the details of feedback questionnaire.

Table 4 Feedback Questionnaire

\begin{tabular}{|c|c|c|c|c|}
\hline \multirow{2}{*}{ Parameter } & \multicolumn{2}{|l|}{ Mean } & \multirow{2}{*}{ t Stat } & \multirow{2}{*}{$\begin{array}{l}\mathrm{P}(\mathrm{T}<=\mathrm{t}) \\
\text { one-tail }\end{array}$} \\
\hline & Before & After & & \\
\hline $\begin{array}{l}\text { Exposure to practical } \\
\text { aspects of the } \\
\text { educational course } \\
\text { which cannot be } \\
\text { visualized in lectures. }\end{array}$ & 4.935 & 8.613 & -17.368 & 0 \\
\hline $\begin{array}{l}\text { Opportunities for } \\
\text { collaborative activities }\end{array}$ & 4.903 & 8.323 & -13.115 & 0 \\
\hline $\begin{array}{l}\text { Ability to understand } \\
\text { the concepts of energy- } \\
\text { conversion process in } \\
\text { electromechanical } \\
\text { systems to non- } \\
\text { electrical engineers }\end{array}$ & 5.161 & 8.306 & -13.619 & 0 \\
\hline $\begin{array}{l}\text { Knowledge of different } \\
\text { types of rotary machines }\end{array}$ & 5.113 & 8.694 & -16.274 & 0 \\
\hline $\begin{array}{l}\text { Ability to identify the } \\
\text { industrial and domestic } \\
\text { applications of actuators }\end{array}$ & 4.887 & 8.500 & -13.867 & 0 \\
\hline $\begin{array}{l}\text { Ability to choose right } \\
\text { sensor to measure all } \\
\text { types of natural } \\
\text { phenomena }\end{array}$ & 4.323 & 8.452 & -16.855 & 0 \\
\hline $\begin{array}{lrr}\text { Exposure to the } & \text { to } \\
\text { importance of safety } \\
\text { precautions } \\
\text { with electricity }\end{array}$ & 5.742 & 8.855 & -17.177 & 0 \\
\hline $\begin{array}{l}\text { Did the activity help in } \\
\text { understanding the } \\
\text { subject better? }\end{array}$ & 4.323 & 8.500 & -13.564 & 0 \\
\hline
\end{tabular}

It is observed statistically that proposed activity has improved the knowledge level of a student. All parameters indicate that there is significant improvement in teams of learning as evidenced by t-value and p-value. Fig.4. depicts the comparison of means of assessment parameters before and after the activity.

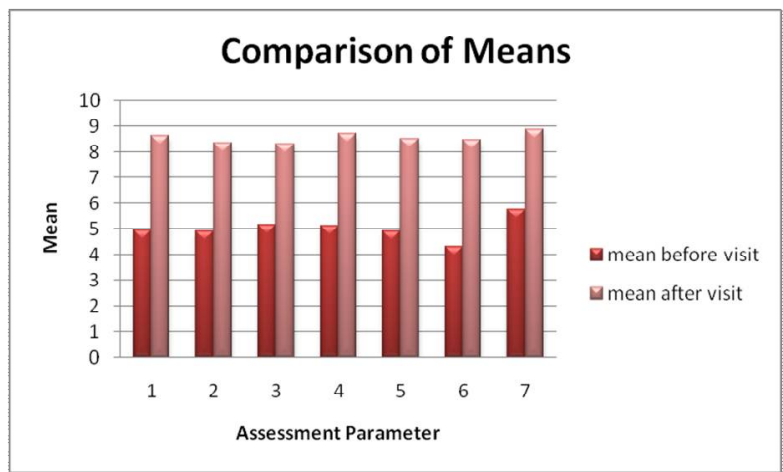

Fig.5 Comparison of Mean before and after Industrial Visit.

\section{Conclusion}

In order to go beyond classroom teaching, the activity was conducted and a model of collaborative experiential model was proposed. It is observed that application of proposed model to the activity has enhanced students learning. Examination results show considerable improvement in answering higher level questions. Feedback analysis shows significant learning after the visit to industry related to the course. Students were able to visualize what is taught in class. Team work helped students in collaborative learning, experiencing new methods to link theory with practical.

\section{REFERENCES}

[1] Fink L. Dee.: Creating Significant Learning Experiences: An Integrated Approach to Designing College Courses, Jossey Bass, 2003

[2] Dick W, Carey L, Carey J.O.: The Systematic Design of Instruction, 6th Edn., Pearson, 2005.

[3] Anna B. Adams, D. Christopher Kayes," Experiential learning in teams", The George Washington University

[4] David W. Johnson,Roger T. Johnson, and Karl A. Smith, " Cooperative Learning: Improving University Instruction By Basing Practice On Validated Theory"

[5] Abel Nyamapfene "Towards a framework for successful learning outcomes in industrial visits", Innovation, Practice and Research in Engineering Education EE2012.

[6] Nirupma Jaimini, "Group Dynamics In Collaborative Learning: Contextual Issues And Considerations" International Journal of Research in Humanities, Arts and Literature (IMPACT: IJRHAL) ISSN(E): 23218878; ISSN(P): 2347-4564 Vol. 2, Issue 2, Feb 2014, $83-88$ 